\title{
BRITISH PAEDIATRIC ASSOCIATION PROCEEDINGS OF THE TWENTIETH GENERAL MEETING
}

The twentieth annual meeting of the British Paediatric Association was held at Windermere on May 4, 5 and 6, 1949.

Business proceedings: The President, Dr. H. T. Ashby, was in the chair, and the following members were present:

Drs. F. M. B. Allen, E. C. Allibone, H. T. Ashby, C. Asher, H. S. Baar, J. M. Bligh, F. Braid, J. V. Braithwaite, R. W. Brookfield, D. Browne, H. C. Cameron, W. H. P. Cant, N. B. Capon, I. A. B. Cathie, C. Chisholm, W. R. F. Collis, T. Colver, B. D. Corner, J. Craig, W. S. Craig, J. Crooks, V. M. Crosse, G. Davison, R. H. Dobbs, E. Dott, A. C. Doyne Bell, R. W. B. Ellis, P. R. Evans, G. B. Fleming, F. J. Ford, A. W. Franklin, D. Gairdner, W. F. Gaisford, S. Graham, C. K. J. Hamilton, A. C. Hampson, E. W. Hart, J. D. Hay, J. L. Henderson, D. V. Hubble, J. H. Hutchison, R. S. Illingworth, N. M. Jacoby, R. C. Jewesbury, H. E. Jones, A. Lichtenstein, R. C. Lightwood, A. MacGregor, H. M. M. Mackay, A. G. Maitland-Jones, F. J. W. Miller, A. Moncrieff, A. E. Naish, A. V. Neale, G. H. Newns, D. N. Nicholson, J. N. O'Reilly, C. G. Parsons, L. Parsons, W. W. Payne, C. P. Pinckney, C. T. Potter, B. Schlesinger, W. P. H. Sheldon, U. Shelley, W. C. Smallwood, J. M. Smellie, J. F. Smith, R. E. Smith, R. E.Steen, K. H. Tallerman, M. L. Thomson, C. W. Vining, H. K. Waller, J. F. Ward, A. G. Watkins, K. D. Wilkinson, T. P. Williams, M. J. Wilmers, W. G. Wyllie.

The Association had the honour of entertaining thirty Swedish paediatricians and twenty other guests.

The minutes of the last annual general meeting were approved.

Election OF OfFICERS: The following were unanimously elected by ballot for the year 1949-50:

President: Dr. A. G. Maitland-Jones.

TREASURER: Dr. R. C. Lightwood.

Secretary: Prof. Alan Moncrieff.

EXECUTIVE COMMITTEE (to replace those retiring):

RePresentative for Provinces : Prof. R. S Illingworth.

RePresentative for Ireland : Prof. F. M. B. Allen.

Co-OPTED SINCE THE last ANNUAL General MEETING:

REPRESENTATIVE FOR LONDON : Dr. R. E. Bonham Carter.

RePRESENTATIVe for Provinces : Dr. D. V. Hubble.
Election of New Members: The following were elected by ballot to membership of the Association:

(a) Honorary Members:

Dr. H. T. Ashby.

Sir Allen Daley.

Dr. A. C. Hampson.

Dr. K. D. Wilkinson.

(b) CoRresponding Members:

Dr. S. L. Ludbrook (Auckland).

Prof. A. Ylppö (Helsinki).

(c) ORDINARY MeMbers:

Dr. I. M. Anderson (London).

Dr. D. Court (Newcastle-on-Tyne).

Dr. E. Mildred Creak (London).

Dr. F. F. Kane (Belfast).

Dr. P. MacArthur (Glasgow).

The Treasurer's RePORT was received and approved.

THE RePORT Of THE EXECUTIVE COMMITte for the year was received and approved and is printed below.

NEXT PLACE OF MEETING: It was reported that it was still hoped to have a joint meeting with colleagues from Canada and the time and place of meeting depended upon this.

Report by the Executive Committee 1948-49

Since the last annual general meeting held at Windermere in April, 1948, the Executive Committee has met on four occasions. The following is a brief summary of the main activities during the year.

1. ApPOINTMENTS AND Distinctions : Congratulations were sent to Professor J. C. Spence on his receiving the honorary D.Sc., Western Australia, and to Dr. F. M. B. Allen on his election to the new chair of child health in Belfast. The Executive Committee also noted with pleasure the promotion of Sir Wilson Jameson to G.C.B. and the knighthood conferred on Sir William Gilliatt, P.R.C.O.G. The following public appointments of members of the Association were also noted with satisfaction:

Professor J. C. Spence to the Central Health Services Council and to the Advisory Committee on Maternity and Midwifery.

Dr. W. Sheldon as paediatric adviser to the Ministry of Health and as a member of the Tuberculosis Advisory Committee.

Dr. A. G. Watkins to the Dental Advisory Committee.

Prof. A. Moncrieff as Chairman of the Home Office Central Advisory Council on Child Care.

The Association will also wish to congratulate Prof. J. C. Spence and Prof. A. Moncrieff on each 230 
being awarded a Dawson Williams Prize of the British Medical Association.

The Association also congratulated Dr. Catherine Chisholm, an honorary member, on election to the F.R.C.P. for special distinction.

2. Obmuary: The Association lost during the year Reginald Miller, an honorary member, one of the original members of the Association and for many years joint editor of the 'Archives of Disease in Childhood.' The death of Dr. F. Tisdall, a corresponding member of Toronto, occurring on April 23, 1949, was also noted with sorrow.

3. Resignations: Dr. H. L. Wallace resigned on going to South Africa, and Dr. Ian Gordon on giving up his work with children.

4. New Societres: The Executive Committee has watched with interest the development of several flourishing regional paediatric societies in accordance with the policy approved last year. Greetings have been sent to newcomers, including the South African Paediatric Society, the Portuguese Paediatric Society, and the Scottish Surgical Paediatric Club.

5. GIFT to THE Associntion: Members will note the new gavel for the use of the chairman, presented by Dr. Henry Helmholz.

6. VISIT To SwEDEN: Twenty-five members of the Association visited Sweden in the summer of 1948 and greatly enjoyed the charming and generous welcome they received. It is with very great pleasure that the Association is able to welcome a party of Swedish colleagues to the annual meeting.

7. MembershiP: Nominations this year again far outnumbered the places available and the Executive Committee has set up a special subcommittee to discuss the whole policy of membership.

8. Archives of Disease in Chillohood. The Association will learn with regret of the resignation of Professor R. W. B. Ellis to take effect at the end of 1949. Dr. P. R. Evans and Dr. I. A. B. Cathie have been proposed as joint editors, and for the Editorial Committee the names of Professors R. W. B. Ellis and W. F. Gaisford to take the place of Sir Leonard Parsons and Dr. C. F. Harris have been put forward to the British Medical Association.

9. Standing Committees and Representatives ON OTHER BODIES: In close collaboration with the Association of Sick Children's Hospital Nurses the nursing sub-committee has continued to urge the importance of the continuation of some form of special training for the nurse in the care of the sick child. The Hospital Architecture and Cross Infection Committee has been discontinued, and a final report on cross infection is being prepared for publication. A new committee to conduct a survey of growth in children has been formed to combine with representatives of the Ministry of Health and the Ministry of Education, and for this investigation an expenses grant has been most generously made to the Association by Messrs. A. and R. Scott, Ltd. The child psychology sub-committee has collaborated with the National Council for Mental
Health in regard to a policy for the future organization for child guidance. The Public Health Committee of the British Medical Association has again co-opted a member of the Association. Professor W. S. Craig was appointed to represent the Association at the Royal Sanitary Institute Congress at Brighton and Dr. R. H. Dobbs to be a 'standing' delegate for meetings arranged by the National Association for Maternity and Child Welfare.

10. Winter Meeting, 1949. Arrangements are being made for a joint meeting with the Maternity and Child Welfare Group, the School Medical Officers' Group, and the Fever Hospital-Medical Officer Group of the Society of Medical Officers of Health to be held at B.M.A. House on Friday and Saturday, Nov. 25 and 26, 1949. The programme will include a discussion on the organization of child health services, the Still Lecture by Professor St. G. Huggett, a session for short communications, and a clinical demonstration.

11. International Congress, 1950. The date of the Sixth International Pediatric. Congress in Zurich has been changed to July 24 to 28,1950 . The Executive Committee has supplied, at the request of Professor Fanconi and his associates, the names of suitable participants in the proposed programme.

12. Annual Meeting, 1950. The suggestion for a joint meeting with Canadian colleagues immediately before the Zurich meeting is still being actively pursued. The date would be approximately July 19 to 21,1950 . A suitable place has not yet been arranged.

13. Neonatal Jonnt Committee Report. The Joint Report of the Royal College of Obstetricians and Gynaecologists and the Association on 'Neonatal Mortality and Morbidity' was published by the Ministry of Health in March and has received favourable comment in the press.

14. Expenses of Commitiee Members. It has been decided that expenses over and above the sum of $£ 20$ per annum incurred by members of the Executive Committee through attending meetings of the committee, other than the meeting held at the same place as the Annual General Meeting, will be repaid to them by the Hon. Treasurer out of the funds of the Association. This decision also applies to members of the Standing Committees appointed by the Executive Committee and to representatives of the Executive Committee attending other bodies.

alan MoncriefF.

Communications
1. DR. E. MANNHEIMER (Stockholm): Cardiac
Catheterization in Congenital Heart Disease.' To be published in the December issue.

2. DR. W. SHELdon (London): 'Coeliac Disease: a Relation between Dietary Starch and Fat Absorption.' See page 81.

3. DR. T. COLVER (Sheffield): 'Aspects of the Natural History of Pink Disease: One Hundred Personally Studied Cases.' This study comprised 
fifty-six males and forty-four females. Of these ninety-one were in the first, eight in the second, and one in the third year of life. Age incidence was maximal between four and ten months. There were four deaths. No particular seasonal incidence was noted. The average duration was 17.8 weeks, and was modified by hospital selection. For instance, cases referred to hospital early had an average total duration shorter than that of cases referred late, chiefly because cases referred late had already proved themselves refractory. As regards duration, therefore, cases referred early were considered more representative of the average. Average duration of cases seen within the first four weeks of the disease was 13.7 weeks, as opposed to twenty-two weeks for cases seen later.

The total duration of disease was not a satisfactory single measurement by which to compare managements, as there was no sharp end point. Duration from onset to the beginning of the recovery phase was, however, a better defined period, and plottings showed that - the improvement began half-way through the disease. Once it occurs the mother can be reassured that, barring intercurrent infection, relapse is unlikely. The first stage of the disease was on the average shorter in the older cases.

A controlled series received weekly injections of vitamins $B 1$ and $B 6$ without demonstrable benefit.

4. DR. K. B. RoGers (Birmingham, introduced by Dr. W. C. Smallwood): 'An Epidemic of Enteritis in Infants: a Bacteriological Study.' Bray, Giles, and Taylor had all found the same serologically specific type of coli associated with epidemics of gastro-enteritis. The same organism was found in three Birmingham hospitals, two of these having epidemics of gastro-enteritis. While its pathogenicity was not proved, because of its very intimate association with cases of gastro-enteritis and its absence in controls, this organism was followed to demonstrate the possible modes of spreading infection. In two hospitals its presence in dust and furnishings explained the possible spread within a ward or cubicle. Finding it on the communal broom and polisher, on a nurse's hand and shoe and on towels, showed ways of spreading infection throughout a cubicle ward.

The efficiency of a suction type cleaner was described: it retained infected dust without allowing any organism to escape; with it wards and cubicles could be cleaned without risk of spreading infected dust.

5. DR. J. P. M. TIZARD (London, introduced by DR. W. G. WyLlie): ' Oesophageal Disorders in Childhood.' An account was given of some findings from a survey of fifty-four cases. Difficulties encountered in diagnosis were discussed.

The series included twenty-seven cases of stenosis, in ten of which the narrowing appeared to be at the site of the cardia in a short oesophagus. In the remaining seventeen it was not found possible to determine whether the stenosis was associated with a short oesophagus or whether it occurred in an oesophagus of normal length.
In contrast there was a group of twelve cases in which refiux of gastric contents led, in early life, to cesophagitis and haematemesis. On endoscopy the oesophagus was seen to be widely dilated at the junction of the oesophageal and gastric mucosae, and under fluoroscopy the distinctive reflux of the barium mixture from the stomach could be observed. The normal mechanism preventing such a reflux was discussed; it was significant that at least six of these cases were examples of short oesophagus with the cardia above the diaphragm.

Amongst the symptoms emphasis was laid on the frequency of projectile vomiting in infancy, both in the stenotic group and in the cases of incompetent cardia, as this had frequently distracted attention from the oesophagus.

The prognosis seemed rather better in the cases of incompetent cardia, in which haematemesis usually ceased when the child began to sit up, while vomiting lasted somewhat longer. In the majority of the stenotic group vomiting continued throughout childhood, but that recovery might ultimately take place without operative treatment was shown in three cases followed up into adult life.

6. Mr. D. Browne (London): 'Two Cases of Stenosis of the Oesophagus.'

7. Dr. J. H. Hutchison (Glasgow): 'Obstructive Emphysema in Primary Tuberculosis.' Obstructive emphysema arises when the air-spaces distal to an incomplete bronchial obstruction become ballooned by air which enters them during inspiration but cannot find egress during expiration, because in this phase the normal constriction of the bronchi causes the obstruction to become complete. This type of emphysema is more often due to primary tuberculosis than to any other cause in infancy and childhood in Great Britain.

Twelve such cases had been met with in the course of three years. Two cases were described in detail, including the radiological and bronchoscopic appearances. In both cases caseous tissue containing tubercle bacilli was removed through the bronchoscope.

The outstanding clinical features in all such cases were the asthmatoid wheeze, which is clearly audible at the open mouth, combined with hyper-resonance to percussion and diminished breath sounds on auscultation. The radiological features were increased translucency, and in severe cases, mediastinal shift to the opposite side, depression of the diaphragm, and widening of the intercostal spaces; all these signs are more marked during expiration.

8. Professor A. Lichtenstein (Stockholm): 'The Treatment of Diabetes in Childhood.' To be published in the December issue.

9. DR. G. van SyDow (Sundsvall): 'Rickets in the Newborn.' In a series of premature infants the serum values of phosphatase became much higher, and those of inorganic phosphorus and calcium much lower than normal during the first few months of life in infants fed exclusively on human milk. Large doses of vitamin D raised the calcium level 
but did not affect the phosphatase and phosphorus levels, whereas cow's milk (i.e. supplementation with minerals) brought the phosphatase and phosphorus levels nearer to normal while leaving the cakcium level unaffected. Supplementation with both vitamin D and cow's milk caused the values of all three substances to approach normal.

In a histological investigation of a series of newborn infants dying in the maternity hospital unmistakable signs of rickets were found in 57 per cent. of all cases. The incidence increased sharply with age.

In view of these findings it must be recognized that in many cases rickets is due to influences affecting the foetus before birth. Taking this into consideration a theory of the pathogenesis of early rickets is formulated and preventive measures are proposed, beginning during pregnancy and including both mineral and vitamin $D$ administration.

10. Dr. I. A. B. CAtriIE (London): 'Bacterial Fibrinolysin.' To facilitate the passage of streptomycin into the gelatinous exudate at the base of the brain in cases of tuberculous meningitis the possibilities of bacterial fibrinolysin have been investigated.

Haemolytic streptococci produce a substance known as streptokinase, capable of causing lysis of fibrin clots formed from plasma. Pieces of fibrinous exudate from fatal cases of meningitis may also be lysed. Streptokinase appears not to be a true lysin but an activator of a naturally occurring profibrinolysin. It may be prepared by absorption from broth cultures of haemolytic streptococci with aluminium hydroxide and elution in phosphate buffer, and the substance is relatively non-toxic to animals. For standardization a fibrin clot is prepared from plasma roughly comparable to a cerebrospinal fluid spider's web' clot. The concentration necessary for the lysis of such a plasma clot in one hour is determined, and for therapeutic trial one hundred times this concentration in $1 \mathrm{ml}$. was chosen, on the assumption that one hundredfold dilution with cerebrospinal fluid occurs on intrathecal injection.

Given therapeutically with streptomycin the streptokinase causes a pleiocytosis and increase of protein in the cerebrospinal fluid, thought to be due in part to the irritant action of the substance and in part to the release of cells and protein from the gelatinous exudate. Tubercle bacilli are also more easily seen and grown.

In a small series of cases treated by the combination of streptomycin and streptokinase the immediate results were considerably better than in a similar series treated with streptomycin alone. Nothing is yet known of the remote results.

11. Dr. P. BraY (Cardiff, introduced by Dr. A. G. Watkins): 'Sino-bronchitis: an Analysis of One Hundred Cases.' Out of 195 children with a chronic cough, 100 were found to have sinusitis associated with bronchopulmonary disease of varying severity. The cases were divided into two groups: asthmatic (44 per cent.) and non-asthmatic (56 per cent.).

Bilateral antral infection was the commonest kind of sinus infection. The associated chest conditions were: (a) bronchitic (44 cases: 10 asthmatic, 34 non-asthmatic); (b) lobular and segmental collapse (26 cases: 15 asthmatic, 11 non-asthmatic); (c) lobar collapse (30 cases: 19 asthmatic, 11 nonasthmatic).

There were fourteen cases of saccular bronchiectasis and twelve cases with slight cylindrical or irregular bronchial dilatation. Two of the latter were reversible.

The following conclusions were drawn:

(1) There is a kind of bronchitis, not obviously asthmatic, which is associated with sinus infection, and will clear up when the sinusitis is cured.

(2) The association of sinusitis and pulmonary collapse often follows pertussis; in this group neither the upper respiratory infection nor the chest condition is readily cured.

(3) In asthmatic children the combination of sinusitis and pulmonary collapse following pertussis leads in a large proportion of the cases to bronchiectasis.

12. Mr. J. Crooks (London): 'The Nature and Treatment of Sinusitis in Children.' In one year at the Hospital for Sick Children, Great Ormond Street, 340 children were found to have infected nasal sinuses. There is a close connexion between sinusitis and infection in the lower respiratory tract. The antra are more commonly infected than the other sinuses, and the onset is usually insidious from repeated upper respiratory infections. The changes in the sinus-lining membranes may be catarmal, polypoid, or suppurative. The age of onset is often in the early school years, but the antra and ethmoids are present at birth, and they may be infected at any age. The symptoms are nasal discharge, nasal obstruction, cough. A child with catarrhal sinusitis may be cured by avoiding repeated infections (best attained by a holiday from school), and by the intranasal use of shrinking drops containing 'ephedrine' to promote drainage of the sinuses. He must be taught to blow his nose. More advanced antrum infection calls for lavage, which can be readily performed under local anaesthesia. Advanced disease of the lining membrane of the antra calls for its removal by radical operation, but this should not be undertaken unless persistent lavage fails to effect a cure.

Mr. Crooks showed a cinema film illustrating antral lavage with local anaesthesia in children.

12a. DR. J. LIND (Stockholm): At the Norrtull Hospital, Stockholm, in 1943 it was observed that out of 133 children ranging in age from $1 \frac{1}{2}$ to 15 years with presenting respiratory infections, 103 patients showed radiological sinus changes, mostly pronounced. Sinusitis is thus extremely common in respiratory infections and common also in children with banal coryza. We have used conservative treatment principally. We have had 
favourable results with penicillin treatment. For the last year we have used penicillin-aerosol and employed a hood of transparent plexiglass with a bottom of soft plastic cloth which can be attached to most commercial penicillin sprays. The concentration of penicillin in the blood was satisfactory even after a short treatment (ten minutes), i.e. $1-\frac{1}{2}$ Oxford units an hour after inhalation.

As it has been possible to establish that the penicillin concentration becomes higher locally than with injection treatment, this form of therapy appears to us to be rational.

12b. Dr. S. Kraepein (Stockholm): At Norrtull's Hospital, Stockholm, during the period from October, 1947, to May, 1948, I began an investigation with Dr. Lind and Dr. Bjuggren with a view to throwing light upon the incidence, nature, duration, and social aspect of sinus affections in ordinary healthy children between the ages of three and six years who were looked after at home, and in those who were placed in day nurseries. Seventy-four children between the ages of three and six years were examined. Each child was examined at least three times at intervals of two months, irrespective of whether there were signs of infection of the upper air passages or not.

We observed that sinus affections were common even in so-called 'healthy' children in the ages of three and six years. About half of the children examined showed antrum change and positive antrum irrigation. No sure distinction can be made between the two categories of children concerning incidence. During a supplementary examination of 80 children (34 'home children' and 46 daynursery children), chosen on the same principles, the incidence of antrum changes was verified.

Sinus affection is often present without the child otherwise showing any symptoms of infection of the upper air passages.

The changes in day-nursery children are notably more severe and protracted than in 'home children.'

There was good agreement between the puncture findings and the changes observed on the radiographs.

13. Dr. B. Vahlouist (Stockholm): 'Serological Immunity in the Newborn Period.' Antibodies may be transferred to offspring via the placenta or in colostrum and milk. In human beings antibodies are easily transferred via the placenta. In many cases, e.g. for diphtheria, tetanus, whooping cough, antistreptolysin, antistaphylolysin, toxoplasma etc., the concentrations of the antibodies are much the same in the blood of the full term infant as in that of the mother. Correspondingly the $\gamma$-globulin concentration at birth is even higher in the child than in the mother.

Antibodies are secreted in human colostrum and to a less extent in milk. It has been a matter of dispute whether the child can utilize these antibodies or not. In order to elucidate this question the author administered orally human serum rich in diphtheria antibodies. In the first few days of life nine out of thirteen infants showed minute absorption, never exceeding 0.3 per cent. of the amount given and usually much lower than that. After the first week a faint trace of absorption could be demonstrated exceptionally. Similar experiments with antibodies of other types, e.g. against whooping cough, are in progress. They will be completed with trials using colostrum rich in antibodies obtained after vaccination during gestation.

DR. H. WALler (London): 'Myoepithelial (Contractile) Cells surrounding the Secreting Alveoli of the Mammary Gland.' Dr. Waller showed slides of sections of the mammary gland of the goat, the work of K. C. Richardson, M.Sc., of University College, London, who has shown the existence of a network of myoepithelial cells, presumably contractile, surrounding the alveoli of the secreting gland. They exist in profusion along the ducts, where they are arranged longitudinally, and in the lacteal sinuses. The cells are distinct from the plain muscle of the gland and appear to furnish the means by which milk is expelled. Mr. Richardson's paper describing the cells and his method of staining them will be published by the Royal Society.

15. DR. R. B. MeYer (Birmingham, introduced by Dr. F. Braid): 'Salt Deficiency as a Cause of Vomiting in Infancy.' A baby who thrived only when taking large quantities of salt by mouth was described. Estimations of urinary sodium and chloride before and after the injection of desoxycorticosterone excluded adrenal hypofunction as a cause of this disorder and suggested that it was due to insensitivity of the renal tubules to the action of adrenal hormone in sodium reabsorption. It is possible that renal sodium leakage is more common than might be thought but that it has previously been missed because of superadded infection, of overreliance on biochemical as opposed to therapeutic tests during the critical stage, and persistent use of small doses of DOCA instead of large amounts of salt on the assumption that marked salt depletion in infancy is due always to adrenal hypofunction. The lesion is probably an isolated one of the renal tubules and would fall into the same class as those in renal acidosis and renal glycosuria.

16. Dr. D. J. Conway (London, introduced by Dr. B. Schlesinger): 'Nephrotic Crises.' In 1940, Farr and MacFadyen in New York described as nephrotic crises the acute febrile bouts, without demonstrable evidence of infection, which occur in nephrotic children and are accompanied by a sudden fall in the serum amino-acid level to $2 \cdot 5 \mathrm{mg}$. or below.

At University College Hospital, London, the similarity of symptoms and signs in these crises has been confirmed. There is a rapid onset of abdominal pain and tenderness, usually without rigidity or inflammation of the abdominal wall, increased skin pallor and lassitude, rapid grunting respirations and pyrexia. Nausea and gaseous abdominal distension are common and a leucocytosis invariable. The condition clears rapidly after one to three days, even without chemotherapy. 
Farr and MacFadyen consider that the crises are due to an acute disturbance of metabolism, because the characteristic fall in serum amino-nitrogen, as measured by the ninhydrin method, does not occur in pharyngitis or otitis media in these children. However, we have noted the same degree of fall in serum amino-acids in pneumococcal meningitis and peritonitis, the common skin erysipeloid which occurs in nephrotic children, and in a child who developed chicken pox. We feel that a similarity of clinical picture and fall in amino-acids does not exclude active infection.

\section{REVIEW}

\section{Amali Italiani di Pediatria}

We have received the first number of this new Italian paediatric journal (Vol. 1, Nos. 1-6, December, 1948), which is to be published bi-monthly at Cagliari, Sardinia. In his foreword the editor, Prof. Macciotta, points out that in spite of the large number of Italian paediatric publications there is still a long time lag between the submission of an article for publication and its appearance in print. This constitutes a serious obstacle to progress which he hopes the new journal will do something to eliminate.

The articles in this first number are followed by summaries in French and English, of which the former are more comprehensible to the Englishman than the latter. In welcoming this new addition to paediatric literature and extending to it our best wishes for the future, we hope that succeeding numbers will, for the benefit of those of us whose Italian is poor, contain more useful English summaries. 